\section{Investigating the Effect of Impurities on Macromolecule Crystal Growth in Microgravity}

Edward H. Snell, ${ }^{*}{ }^{\dagger}$ Russell A. J udge, ${ }^{\dagger}$ Lisa Crawford, ${ }^{\dagger}$ Elizabeth L. Forsythe, ${ }^{\dagger}$ Marc L. Pusey, ${ }^{\dagger}$ Michael Sportiello, ${ }^{\ddagger}$ Paul Todd, ${ }^{\ddagger}$ Henry Bellamy, ${ }^{\S}$ J eff Lovelace," J ohn M. Cassanto, ${ }^{\perp}$ and Gloria E. O. BorgstahllI

Biophysics SD48, NASA MSFC, Huntsville, Alabama 35812, Department of Chemical Engineering, University of Colorado at Boulder, Boulder, Col orado, 80309-0424, Stanford Synchrotron Radiati on Laboratory, 2575 Sand Hill Road, MS 69, Menlo Park, California 94025, Department of Chemistry, The University of Toledo, 2801 West Bancroft Street, Toledo, Ohio 43606, and Instrumentation Technol ogy Associates,

Exton, Pennsylvania 19341

Received December 15, 2000

\begin{abstract}
Chicken egg-white lysozyme (CEWL) crystals were grown in microgravity and on the ground in the presence of various amounts of a naturally occurring lysozyme dimer impurity. No significant favorable differences in impurity incorporation between microgravity and ground crystal samples were observed. At low impurity concentration the microgravity crystals preferentially incorporated the dimer. The presence of the dimer in the crystal lization solutions in microgravity reduced crystal size, increased mosaicity, and reduced the signal-to-noise ratio of the X-ray data. Microgravity samples proved more sensitive to impurity. Accurate indexing of the reflections proved critical to the X-ray analysis. The largest crystals with the best X-ray diffraction properties were grown from pure solution in microgravity.
\end{abstract}

\section{Introduction}

The reduced acceleration environment of an orbiting spacecraft, colloquially termed microgravity, is seen as an environmental variable that has the potential to improve the quality of crystals for structural studies. ${ }^{1}$ The experiments are small, have low mass, can be remotely operated, and potentially have a high scientific and commercial payback. To date, growth of macromolecular crystals in microgravity has had mixed results, with enhancement in some studies ${ }^{2-5}$ and no positive or even detrimental effects in others. ${ }^{6-8}$ CEWL, a frequent flyer in microgravity crystallization programs, reflects this variation with reports of decreased mosaicity, 4,9 increased diffraction resolution, ${ }^{10}$ marginal improvement, ${ }^{11}$ and no effects. ${ }^{7-8}$

In biological crystal growth, macromolecule purity is frequently given as a major parameter governing success in crystal lization. Purity requires both the removal of other protein species and the elimination of heterogeneity within the macromolecule to be crystallized. ${ }^{12}$ Structurally dissimilar impurities are more likely to be rejected by growing crystals. ${ }^{13-14}$ However, they may interfere with the nucleation process and may cause increased twinning ${ }^{15}$ and loss of faceted faces. ${ }^{13,16}$ Impurities structurally similar to the macromolecule of interest are more likely to be incorporated into the crystal in significant quantities. ${ }^{15-17}$ This may result in significant changes in crystal morphology due to slower growth on one crystal face relative to another, which

* To whom correspondence should be addressed. Phone: (256) 544 5570. Fax: (256) 544-9305. E-mail: eddie.snell@msfc.nasa.gov. E.H.S and R.A.J . contributed equally to this work.

† NASA MSFC.

₹ University of Colorado at Boulder.

$\S$ Stanford Synchrotron Radiation Laboratory.

"The University of Toledo.

$\perp$ Instrumentation Technology Associates. results in a shortening ${ }^{17,18}$ or lengthening of the crystal ${ }^{19}$ in comparison to those grown in pure solutions.

While impurities may affect our ability to produce crystals of the desired volume and morphology, their effect upon the X-ray diffraction analysis is also of great interest. Results using lysozyme as a model system have been impurity-specific. For CEWL crystallized in the presence of structurally different impurities, ovalbumin $5 \%(\mathrm{w} / \mathrm{w})^{13}$ and ovotransferrin up to $10 \%(\mathrm{w} / \mathrm{w}),{ }^{16}$ no difference in diffraction resolution was found in comparison to crystals grown in pure solutions. Similar results have been reported for some studies using structurally similar impurities. For example, CEWL crystals grown in the presence of up to $20 \%(\mathrm{w} / \mathrm{w})$ turkey egg white lysozyme (TEWL) contained about 10\% (w/ w) impurity, yet there was no difference in diffraction resolution. ${ }^{16}$ In the reverse scenario, where TEWL was crystallized in the presence of CEWL, with $24 \%$ impurity incorporation, again no significant difference in diffraction resolution was reported. ${ }^{17} \mathrm{H}$ owever, a naturally occurring covalent dimer of CEWL 20 is incorporated into CEWL crystals in significant quantities and exhibits detrimental effects on diffraction resolution. ${ }^{10}$ In microgravity experiments CEWL crystals were reported to have reduced incorporation of this impurity relative to ground-based experiments and exhibited improved diffraction resolution and lower isotropic B-factors. ${ }^{10}$ It was postulated that this may be due to the depletion zone formed around the crystal in microgravity serving as a diffusive-barrier filter, effectively reducing the incorporation of larger, slow-moving impurities. ${ }^{10,21}$ To further explore the interesting issue of what role microgravity and impurities play in the improvement of crystal quality, we carried out flight experiments incorporating ground controls, detailed $X$-ray resolution and mosaicity analysis, and electrophoretic measurements of impurity partitioning. 
Table 1. Experimental Data Collection Parameters and Crystal Sizesa

\begin{tabular}{|c|c|c|c|c|c|c|c|c|}
\hline \multirow[b]{2}{*}{ cryst } & \multirow[b]{2}{*}{ dimer } & \multirow[b]{2}{*}{ size (mm) } & \multicolumn{2}{|c|}{ coarse collection } & \multicolumn{2}{|c|}{ superfine collection } & \multirow[b]{2}{*}{ cell params $a=b, c(\AA)$} & \multirow[b]{2}{*}{ date collected } \\
\hline & & & time (s) & images & time (s) & images & & \\
\hline \multirow[t]{5}{*}{ microgravity } & $0 \%$ & $1.12 \times 0.96 \times 0.72$ & 20 & 20 & 2 & 2000 & 78.93, 38.02 & 7/99 \\
\hline & $0.5 \%$ & $0.62 \times 0.61 \times 0.37$ & 120 & 20 & 5 & 2000 & $78.51,37.50$ & $11 / 98$ \\
\hline & $0.9 \%$ & $0.40 \times 0.26 \times 0.19$ & 60 & 20 & 5 & 1000 & 78.87,37.87 & $11 / 98$ \\
\hline & $1.8 \%$ & $0.32 \times 0.28 \times 0.13$ & 120 & 20 & 5 & 2000 & $79.09,38.00$ & $11 / 98$ \\
\hline & $3.6 \%$ & $0.54 \times 0.37 \times 0.26$ & 60 & 20 & 5 & 2000 & $78.89,38.06$ & $11 / 98$ \\
\hline \multirow[t]{2}{*}{ ground } & $0 \%$ & $0.86 \times 0.40 \times 0.40$ & 20 & 20 & 2 & 2000 & 79.09, 38.09 & $7 / 99$ \\
\hline & $3.6 \%$ & $0.48 \times 0.35 \times 0.32$ & 15 & 20 & 4 & 2000 & 78.87, 38.07 & $7 / 99$ \\
\hline
\end{tabular}

a The size was evaluated by measuring the largest dimension and then the other two perpendicular dimensions. For each crystal two $10^{\circ}$ swaths of coarse data with $\Delta \phi=1^{\circ}$ were collected $90^{\circ}$ apart. Two $1^{\circ}$ swaths of superfine $\phi$ sliced data as $0.001^{\circ}$ separated stills were then collected. For the ground $3.6 \%$ case swaths were collected $45^{\circ}$ apart. The space group for all crystals was $\mathrm{P} 4_{3} 22_{1} 2$.

\section{Experimental Method}

2.1. Protein Preparation. Lysozyme was extracted directly from fresh chicken eggs and purified using a two-step cation exchange chromatography technique. ${ }^{14}$ Late-eluting fractions containing the dimer were also collected, concentrated, dialyzed against pH 7.0 0.05 M sodium phosphate, and further purified with a semipreparative cation exchange HPLC column (HEMA-IEC SB, $22.5 \times 250 \mathrm{~mm}$, Alltech Associates Inc.) eluted with a $\mathrm{NaCl}$ gradient. Purified dimer was pooled, concentrated by ultrafiltration (Amicon), and stored at $4{ }^{\circ} \mathrm{C}$ until used. Lysozyme solution concentrations were cal culated on the basis of UV absorbance measurements using an extinction coefficient of $A(1 \%, 1 \mathrm{~cm}, 281.5 \mathrm{~nm})=26.4 .^{22}$ Activity of the lysozyme dimer preparation was measured using the Micrococcus Iysodeikticus assay. ${ }^{23}$ Lysozyme dimer and monomer peptide analysis was performed after tryptic and chymotryptic digestion of the carboxymethylated protein, by reverse-phase HPLC (Varian 9050Q, Varian Chromatography Systems) according to the method of Mayes. ${ }^{24}$

2.2. Crystallization. Crystallization in microgravity took place on the U.S. Space Shuttle STS-95 mission. This 9 day mission was launched on October 29th, 1998. Crystals were grown by liquid-liquid diffusion in the Dual Materials Dispersi on Apparatus (DMDA) (Instrumentation Technology Associates). The DMDA is a multiwell apparatus of a sliding block design. ${ }^{25}$ The top and bottom wells of each experiment contained $122 \mu \mathrm{L}$ of $7 \% \mathrm{w} / \mathrm{v} \mathrm{NaCl}$ solution and $105 \mu \mathrm{L}$ of $7 \% \mathrm{w} / \mathrm{v}$ lysozyme solution, respectively. The equilibrium precipitant concentration was $3.76 \%$. Both salt and protein solutions also contained $0.1 \mathrm{M}$ sodium acetate buffer at $\mathrm{pH}$ 4.8. I nitially separated, the experiment was activated after reaching low Earth orbit by bringing both wells into alignment. This allowed the solutions to diffuse into each other across a liquid-liquid interface. Experiments were conducted at $20^{\circ} \mathrm{C}$ and contained various added concentrations of the lysozyme dimer. Approximately $6 \mathrm{~h}$ after landing the crystals were harvested from the DMDA using the existing mother liquor. The wells were then rinsed with an artificial mother liquor to recover any remaining crystals. Crystal samples were returned to the University of Colorado at Boulder and then transported in large capillary tubes to NASA, Marshall Space Flight Center (MSFC), where they were stored at $22^{\circ} \mathrm{C}$.

The ground crystallization experiments were conducted in 96-well plates at the same temperature and using the same solutions as used in the microgravity mission. In an attempt to mimic the liquid-liquid interface diffusion experiments conducted in microgravity, the same solution volumes and concentrations were used. The precipitant solution was placed first in the well, and the protein solution was gently overlayered on top of it. The plate was sealed with transparent tape and incubated for a time period similar to that used in the mission. Crystallization experiments conducted at different precipitant concentrations were performed in the same way with the same initial supersaturation $(\ln (c / s)=2.25$, where $c$ is the bulk solution concentration and $\mathrm{s}$ is the solubility) and initially contained 3.6\% (w/w) dimer.

2.3. Crystal Measurements. Crystal size and axial ratios were measured using a microscope connected to an image processor which had been calibrated with a standard size grid. These techniques have been described in detail elsewhere. ${ }^{26}$

2.4. Electrophoretic Analysis of Impurity Partitioning. The microgravity- and Earth-grown crystals were washed twice $(4 \% \mathrm{NaCl}, 0.1 \mathrm{M}$ sodium acetate buffer $\mathrm{pH} 4.8$ and 3 $\mathrm{mg} / \mathrm{mL}$ purified CEWL) and dissolved in water, and the solutions were concentrated. (Before dissolution, wash liquid was removed from the crystals as thoroughly as possible using pipets and filter paper strips. Whilea minimal amount of wash liquid was dissolved with the crystals, the wash solution was dilute and calculations were performed that indicated this affected the analysis of the dimer content of the crystals by less than $0.05 \%$ (w/w, dimer/monomer).) For the experiments conducted at different precipitant concentrations, the wash solutions were set close to solubility. They were as follows: 0.1 $\mathrm{M}$ sodium acetate, $\mathrm{pH} 4.8$ with $2.8 \%(\mathrm{w} / \mathrm{v}) \mathrm{NaCl}, 10.1 \mathrm{mg} / \mathrm{mL}$ of CEWL; $5 \%(\mathrm{w} / \mathrm{v}) \mathrm{NaCl}, 2.1 \mathrm{mg} / \mathrm{mL}$ of CEWL; 7\% (w/v) NaCl, $1.7 \mathrm{mg} / \mathrm{mL}$ of CEWL. Dissolved crystals were subjected to SDSPAGE analysis with Coomassie blue stain using a PHASTSYSTEM with $8-25 \%$ gradient gels (Pharmacia LKB Biotechnology). CEWL and the dimer were quantified using CE WL standards run on the same gel with gels being run in duplicate and scanned by a densitometer for quantitation. The effective partitioning coefficient $\left(\mathrm{K}_{\text {eff }}\right)$ was calculated as reported by Carter et al. ${ }^{10}$ and Thomas et al. ${ }^{27}$

$$
\mathrm{K}_{\text {eff }}=\left(\mathrm{C}_{\mathrm{iS}} / \mathrm{C}_{\mathrm{pS}}\right) /\left(\mathrm{C}_{\mathrm{iL}} / \mathrm{C}_{\mathrm{pL}}\right)
$$

where $\mathrm{C}_{\mathrm{is}}, \mathrm{C}_{\mathrm{ps}}, \mathrm{C}_{\mathrm{iL}}$, and $\mathrm{C}_{\mathrm{pL}}$ are the concentrations of impurity in the solid crystal, of the major protein in the crystal, of impurity in the initial solution and of the major protein in the initial solution, respectively. The concentrations are averages over the crystals in the well and the solution vol ume. If $\mathrm{K}_{\text {eff }}>$ 1 , then a greater proportion of impurity is found in the crystal than in the initial solution, and if $K_{\text {eff }}<1$, then impurity is being excluded from the crystal and the crystallization process is acting as a purification mechanism.

2.5. X-ray Analysis. The experimental setup for measuring crystal mosaicity and diffraction resolution using unfocused monochromatic synchrotron radiation in combination with superfine $\phi$ slicing was as described in detail elsewhere. ${ }^{28,29}$ Crystals were mounted in quartz glass capillaries, and data were collected at $22{ }^{\circ} \mathrm{C}$. Temperature was controlled by a regulated nitrogen gas stream. The coarse data were processed with MOSFL $\mathrm{M}^{30}$ and reduced with CCP $4^{31}$ packages. For each crystal two orthogonal swaths of coarse $\left(\Delta \phi=1^{\circ}\right)$ and superfine $\left(\Delta \phi=0.001^{\circ}\right) \mathrm{X}$-ray diffraction data were collected (Table 1$)$. The superfine $\phi$ sliced data were processed to evaluate the reflection profiles and deconvolute Lorentz, geometrical, and spectral effects using the program Beamish.28,29 A signal-tonoise cutoff of $5 \sigma$ was used, and negative mosaicities were discarded as partials.

2.6. Anisotropic Mosaicity Calculation. Ferrer \& Roth ${ }^{32}$ described a mosaicity model in terms of the crystallographic directions $h, k$, and I. This model was reformulated for the 


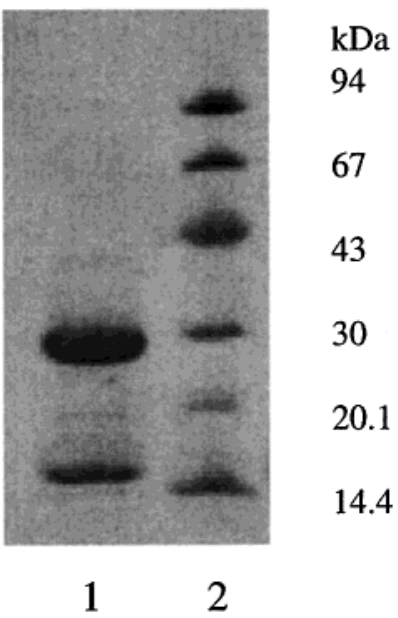

Figure 1. SDS PAGE analysis of lysozyme dimer preparation: (lane 1) lysozyme dimer preparation (at $28 \mathrm{kDa}$ ); (lane 2) molecular weight standards.

general case as

$$
\begin{aligned}
& \eta_{\mathrm{hkl}}^{\text {calcd }}=\left[\eta_{\mathrm{abc}}\left(\frac{(\mathrm{ah})^{2}+(\mathrm{bk})^{2}+(\mathrm{dl})^{2}}{\mathrm{a}^{2}+\mathrm{b}^{2}+\mathrm{c}^{2}}\right)+\right. \\
& \left.\eta_{\mathrm{def}}\left(\frac{(\mathrm{dh})^{2}+(\mathrm{ek})^{2}+(\mathrm{fl})^{2}}{\mathrm{~d}^{2}+\mathrm{e}^{2}+\mathrm{f}^{2}}\right)+\eta_{\mathrm{mno}}\left(\frac{(\mathrm{mh})^{2}+(\mathrm{nk})^{2}+(\mathrm{ol})^{2}}{\mathrm{~m}^{2}+\mathrm{n}^{2}+\mathrm{o}^{2}}\right)\right] / \\
& \left(\mathrm{h}^{2}+\mathrm{k}^{2}+\mathrm{l}^{2}\right)+\eta_{\text {const }}
\end{aligned}
$$

where $(a, b, c),(d, e, f)$, and $(m, n, 0)$ define Bragg planes. The model was fit to the measured deconvoluted mosaicity data using a multivariate regression analysis. Two sets of planes were fit to the data, one al ong the crystallographic axes $(1,0,0)$, $(0,1,0)$, and $(0,0,1)$ by the method of Ferrer and Roth 32 and the other along the growth directions of the crystals $(1,1,0)$, $(1,0,1)$, and $(0,1,1)$. The isotropic component, $\eta_{\text {const }}$, was set to zero. A sample coefficient of multiple determination, $\mathrm{R}^{2}$ (where $\mathrm{R}^{2} \times 100 \%$ is the percentage of the data that can be fitted with the model), of the model was calculated to describe the goodness of fit. The data were fitted to several Gaussians with the assumption of a linear background as described elsewhere. 28,29

2.7. Microgravity Environment. The microgravity environment can be monitored by accelerometers. On the STS-95 mission a Space Acceleration Measurement System for FreeFlyers (SAMS-FF) was mounted toward the rear of the orbiter as part of an experiment to measure vibrations of a cryogenic cooling system destined for the Hubble Space Telescope. The crystallization experiments were accommodated in Spacehab some distance from the accel erometers. Consequently, there are no accelerometer data on the microgravity environment determined at the locus of the experiments. Previous studies ${ }^{33-35}$ illustrate that different acceleration environments can have different effects on the crystal growth. The lack of these data makes comparison between different missions difficult.

\section{Results and Discussion}

3.1. Lysozyme Dimer Preparation. SDS PAGE electrophoresis of the preparation revealed the dimer (28 kDa) and a second band at $14.4 \mathrm{kDa}$ (Figure 1). This second band is likely monomeric lysozyme, as evidenced by the molecular weight and previously reported attempts at dimer purification. ${ }^{20}$ Further, residue analysis after protease digestion was identical for both the dimer preparation and that of pure monomeric lysozyme. When a quantitated dimer purity of $86 \%$ (w/w total

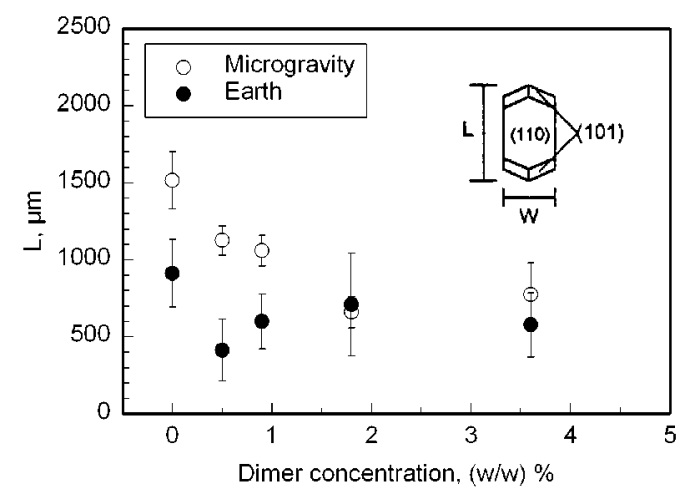

Figure 2. Effect of dimer concentration on maximum crystal size for the microgravity- and ground-grown crystallization experiments. The distance $L$ is defined as the distance between the apexes of the $\{101\}$ faces. Data points represent the average of duplicate experiments. The error bars represent the range of the data based on the results from duplicate experiments.

Table 2. Partitioning Coefficients ( $\left.K_{\text {eff }}\right)$ of the Lysozyme Dimer in Microgravity and Ground Control Crystallization Experiments ${ }^{\mathrm{a}}$

\begin{tabular}{lllll}
\hline & \multicolumn{4}{c}{ dimer \% (w/w) } \\
\cline { 2 - 5 } & 0.5 & 0.9 & 1.8 & 3.6 \\
\hline ground & 0.3 & 0.7 & 1.0 & 1.0 \\
microgravity & 2.0 & 1.2 & 0.6 & 0.7 \\
error & 0.2 & 0.3 & 0.3 & 0.4
\end{tabular}

a Errors were assessed from duplicate gels run on the ground samples.

protein) was taken into account, the activity of the dimer (Units/mg of protein) was $\sim 34 \%$ of that found for lysozyme prepared from fresh chicken eggs. Back 20 also reported reduced lysozyme activity of the dimer and postulated that the linkage of the monomers forming the dimer causes a steric hindrance between the lysozyme active sites and the bacterial cell wall.

3.2. Crystal Size and Morphology. For both the microgravity and ground control experiments the size of the largest crystal in each crystallization chamber was recorded. In all cases the largest dimension was between the apexes of the $\{101\}$ faces, given as $L$ in Figure 2. While the data are limited, some tentative trends are found. There is no apparent effect of dimer concentration on the size of the ground-grown crystals. In the microgravity-grown crystals there is a decrease in crystal size with increasing dimer concentration. Additionally, at low dimer concentration ( $<1$ (w/w)\%) the microgravity-grown crystals were significantly larger than their Earth-grown counterparts, while at higher dimer concentrations there was little difference. The crystal axial ratio (L/W; Figure 2) was the same for both microgravity- and Earth-grown crystals $(1.7 \pm 0.2)$ and independent of dimer concentration. The decrease in crystal size with increasing dimer concentration in microgravity appears ther efore to be an equival ent effect of the dimer on all crystal faces and does not represent a preferential shortening of a crystal axis, as has been reported for some crystallization systems. ${ }^{18}$

3.3. Partitioning in Microgravity. Partitioning coefficients ( $\mathrm{K}_{\text {eff }}$ in Table 2 ) for the microgravity and ground control experiments were determined by electrophoretic analysis. Given the size of the errors, based on duplicate gel results, there appears to be no signifi- 
cant difference in the $K_{\text {eff }}$ values between the two growth environments for initial dimer concentrations of 3.6, 1.8, and $0.9 \%(w / w)$, with $K_{\text {eff }}$ being close to unity. At the lowest dimer concentration, however, there does appear to be a substantial difference in $\mathrm{K}_{\text {eff }}$ with lower incorporation on the ground. Microgravity-grown crystals preferentially incorporate the dimer at the $0.5 \%(\mathrm{w} / \mathrm{w})$ concentration. This illustrates an interesting and significant but complex effect of concentration on impurity partitioning. More data will be needed to illuminate this effect.

For comparison, a dimer partitioning coefficient was estimated using mass balance techniques (see Supporting I nformation), using data published by Thomas et al. $(1998)^{36}$ for dimer incorporation in ground-based batch Iysozyme crystallization experiments. For an initial $1 \%$ dimer concentration at $\mathrm{pH} 4.5(0.05 \mathrm{M}$ sodium acetate buffer) and $2.5 \%(\mathrm{w} / \mathrm{v}) \mathrm{NaCl}$, at $4{ }^{\circ} \mathrm{C}$ a value of $K_{\text {eff }}$ value of $\leq 0.9$ was calculated from these published data. ${ }^{36}$ This is in good agreement with our findings of $\mathrm{K}_{\text {eff }}=0.7 \pm 0.3$ for $0.9 \%$ initial dimer concentration.

Another study 10 with CEWL using the Diffusioncontrolled Crystallization Apparatus for Microgravity $(D C A M)^{37}$ at ambient temperature aboard the Mir spacestation reported $\mathrm{K}_{\text {eff }}$ values of 9 on the ground and 2 in microgravity, assuming an initial 1\% dimer solution concentration. Given that experimental conditions may influence $K_{\text {eff, }}$ it is difficult to make a direct comparison between these two findings. Under the solution conditions examined in this study with $0.9 \%(\mathrm{w} / \mathrm{w})$ dimer concentration, the Earth and microgravity partitioning coefficients $\left(K_{\text {eff }}\right)$ are about factors of 10 and 2 less, respectively, than that reported ${ }^{10}$ for a $1 \%(w / w)$ dimer concentration. The significant difference in these two studies with similar, but not identical, conditions indicates a strong trend in $\mathrm{K}_{\text {eff }}$ with solution parameters and perhaps even with the method of crystallization. For example, the liquid-liquid technique used in this study, with its small solution volumes, is likely to come to equilibrium faster and crystal lize over a shorter time period than in the operation of a DCAM. Given the long duration of experiments on Mir, another possibility could be dimer formation through aging. Our samples were analyzed as soon as possible after their return.

3.4. X-ray Analysis. The beam time at Stanford Synchrotron Radiation Laboratory (SSRL) became available 1 month after the return of the mission. Because of constraints on beam time, an additional run was conducted at SSRL some 6 months after the flight (Table 1). Single, unattached crystals were chosen for X-ray analysis. Visual comparison of the diffraction images from mi crogravity and Earth crystals with no impurity present indicates an increased strength of the diffraction intensity and resolution for the microgravity crystal (Figure 3). This is also reflected in Figure 4, which illustrates a marked improvement in the signal-to-noise ratio throughout the diffracting range. Microgravity crystals grown from solutions with initial dimer concentrations of $0.9 \%$ and $3.6 \%(w / w)$, (Figure $3 c, d)$ gave a reduced diffraction limit compared to those grown in pure solution (Figure 3a). Figure 5 shows plots of intensity (normalized for exposure time and background subtracted) against the dimer concentration. The ground data, $0 \%$ and $3.6 \%$, are not significantly different. For

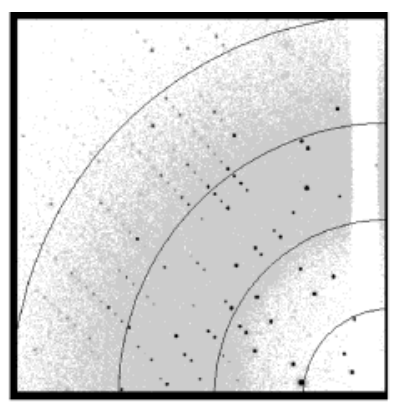

(a)

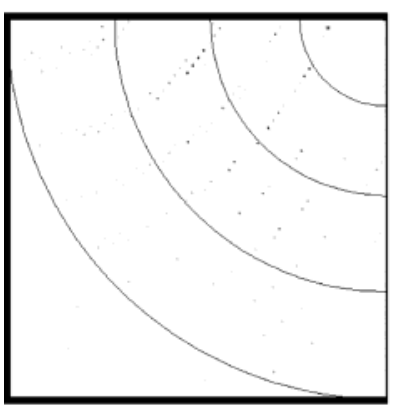

(c)

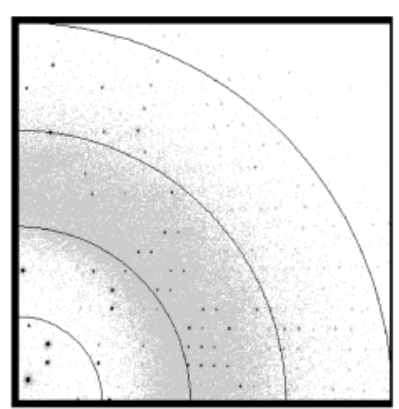

(b)

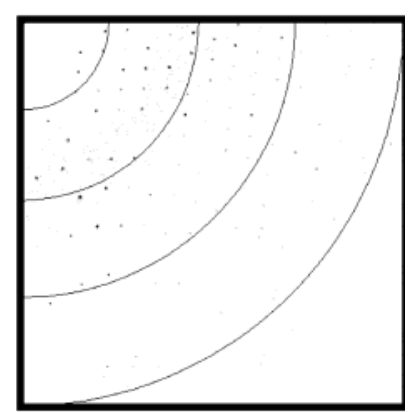

(d)
Figure 3. Four $1^{\circ}$ oscillation quadrant images shown on the same intensity scale. The images were collected in unfocused mode on SSRL beamline 1-5 using an ADSC Quantum IV CCD detector. Microgravity and ground samples with pure lysozyme are seen in (a) and (b) with identical exposure times (20 s). Microgravity samples with $0.9 \%$ and $3.6 \%$ impurity are seen in (c) and (d), respectively (60 s exposure). In this figure the rotation axis is vertical and the beamstop is seen as a horizontal white shadow in (a). Each quadrant is taken from a random orientation of the sample. The circles from the inside out are at 8.0, 4.0, 2.7, and $2.0 \AA$ resolution, respectively. Strong diffraction is seen in the Lorentz region (the vertical axis), where reflections pass through the E wald sphere slowly. The ground $3.6 \%$ dimer sample was too weak to be seen on this plot. The images are rotated by $90^{\circ}$ from their recorded orientation.

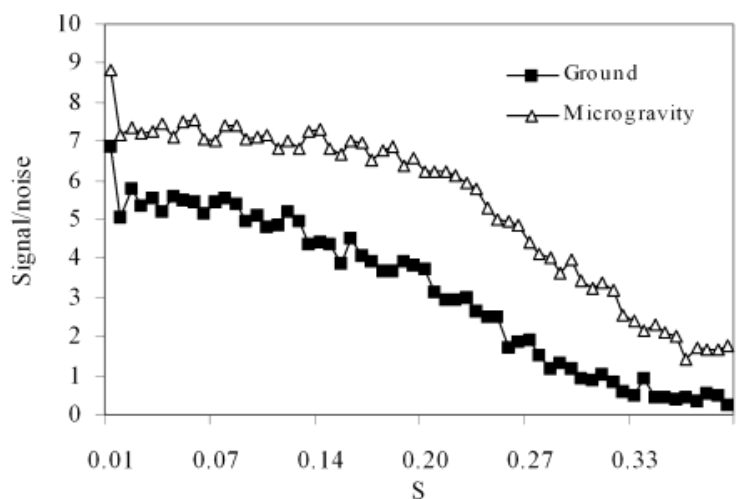

Figure 4. Signal-to-noise pl ot for microgravity and ground crystals grown from pure solutions, $S=4(\sin \theta / \lambda)^{2}$.

the $0 \%$ microgravity sample there is at least a 4 -fold increase in the intensity of the reflections in the greater than $2.0 \AA$ resolution bin in comparison to its Earth counterpart. The same result is reflected in other resolution bins. The disparity in crystal volumes, a result of microgravity growth and dimer incorporation, is probably the dominant reason for the increased strength of diffraction. 
Table 3. Anisotropic Refinement of Mosaicities ${ }^{a}$

\begin{tabular}{|c|c|c|c|c|c|c|c|c|c|c|c|c|c|c|c|c|c|}
\hline \multirow[b]{2}{*}{ cryst } & \multirow{2}{*}{$\begin{array}{c}\text { dimer } \\
\%\end{array}$} & \multirow[b]{2}{*}{$\eta(\mathrm{av})$} & \multicolumn{3}{|c|}{$\begin{array}{l}\text { mosaicity } \\
(h, k, l)\end{array}$} & \multicolumn{3}{|c|}{$\begin{array}{c}\text { mosaicity } \\
\text { (growth face) }\end{array}$} & \multirow[b]{2}{*}{$\mathrm{R}^{2}$} & \multirow{2}{*}{$\begin{array}{c}\text { no. of } \\
\text { ref }\end{array}$} & \multirow{2}{*}{$\begin{array}{c}\text { no. } \\
\text { Gauss }\end{array}$} & \multicolumn{3}{|c|}{$\begin{array}{l}\% \text { rflns fitted } \\
\text { by Gaussians }\end{array}$} & \multicolumn{3}{|c|}{ av mosaicity, $\eta$} \\
\hline & & & $\eta_{\mathrm{h}}$ & $\eta_{\mathrm{k}}$ & $\eta_{1}$ & $\eta_{110}$ & $\eta_{101}$ & $\eta_{011}$ & & & & 1 & 2 & 3 & 1 & 2 & 3 \\
\hline \multirow[t]{2}{*}{ Earth } & 0.0 & $8.4(3.3)$ & 4.1 & 8.3 & 14.4 & -0.1 & 5.1 & 9.3 & 0.12 & 857 & $2(1)$ & 27.8 & 72.2 & & $4.0(1.7)$ & $5.4(1.8)$ & \\
\hline & 3.6 & $6.6(2.6)$ & 6.8 & 6.2 & 5.4 & 3.8 & 3.0 & 2.4 & 0.09 & 451 & 2 & 1.7 & 98.3 & & $4.4(2.1)$ & $3.9(1.7)$ & \\
\hline \multirow[t]{5}{*}{ micro } & 0.0 & $6.5(1.8)$ & 5.5 & 7.0 & 8.5 & 2.0 & 3.5 & 5.0 & 0.04 & 1499 & 2 & 13.1 & 85.6 & & $5.3(1.2)$ & $3.9(1.6)$ & \\
\hline & 0.5 & $6.2(2.1)$ & 6.8 & 5.6 & 6.0 & 3.2 & 3.6 & 2.4 & 0.03 & 1305 & 2 & 1.4 & 93.7 & & $4.9(10.9)$ & $4.0(4.7)$ & \\
\hline & 0.9 & $10.2(7.0)$ & 8.2 & 10.8 & 15.6 & 1.7 & 6.5 & 9.1 & 0.04 & $931^{b}$ & 2 & 29.0 & 71.0 & & $9.9(7.4)$ & $9.5(6.7)$ & \\
\hline & 1.8 & $16.0(6.2)$ & 20.6 & 14.1 & 8.7 & 13.0 & 7.6 & 1.1 & 0.18 & 911 & 3 & 3.2 & 42.0 & 54.8 & 15.4(16.6) & $18.5(5.6)$ & $31.5(71.1)$ \\
\hline & 3.6 & 7.4(1.7) & 8.5 & 7.5 & 3.2 & 6.4 & 2.1 & 1.1 & 0.12 & 1107 & 2 & 1.0 & 99.0 & & $5.5(2.9)$ & $5.7(2.4)$ & \\
\hline
\end{tabular}

${ }^{a} R^{2}$ is the goodness of fit of the anisotropic mosaicity. The number of Gaussians fitted to the data is also noted with the percentage of reflections fitted. For the $0 \%$ dimer Earth sample the two swaths of data collected were fitted to one and two Gaussians, respectively. The average mosai city for each Gaussian is noted with the standard deviation in brackets, both in thousandths of a degree. Because of differences in exposure times (Table 1 ) it is inappropriate to compare the number of reflections between crystals. ${ }^{\mathrm{b}} \mathrm{N}$ ote that only $1^{\circ}$ of data was collected for the $0.9 \%$ superfine sliced data, in comparison with $2^{\circ}$ for the rest of the data.

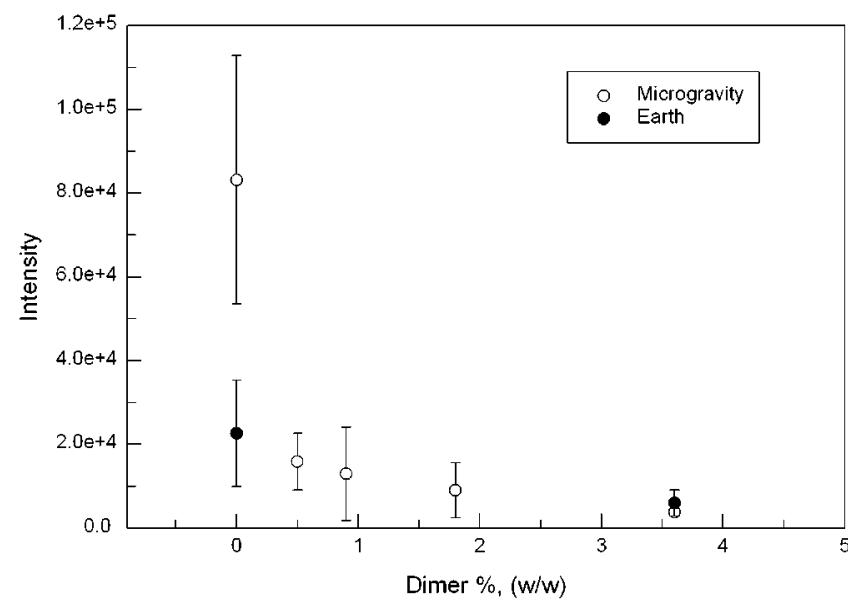

Figure 5. Intensity plotted against the initial dimer solution concentration for highest resolution bracket greater than 2.01 $\AA$. Other resolution bins display similar trends. The error bars represent $95 \%$ confidence intervals. Different reflections have different intensties. The average intensity is plotted with the error representing the spread in intensity associated with those different reflections.

For average mosaicity values (Table 3), the effect of impurity appears, at first, to be unclear. Among the microgravity crystals only the $1.8 \%$ crystal is statistically distinct from the average of all the crystals. It is possible that the crystal could have been damaged during mounting, al though care was taken to treat each crystal identically. The two ground crystals also show no significant variation with impurity concentration (Table 3) and are not significantly different from their microgravity counterparts. Mosaicity also shows little change with resolution, with the exception of the 1.8\% dimer impurity in the mi crogravity case (Figure 6). The linearity is expected if there is little or no contribution of the mosaicity to internal domain variation. ${ }^{38,39} \mathrm{~F}$ or the $1.8 \%$ dimer case, mosaicity increases with resolution. This is indicative of disorder within the individual domains that make up the crystal. The data from the $0.9 \%$ dimer doped crystal extend to lower resolution, because the volume of reciprocal space sampled is less and the data are binned to give approximately equal number of reflections in each bin.

The directional components of crystal mosaicity, analyzed using an anisotropic model ${ }^{28,32}$ (Table 3), show that when dimer concentration is increased mosaicity seen in the $h$ direction, $\eta_{\mathrm{h}}$, increases with dimer content, becoming maximum at the $1.8 \%$ level (4 times that of the pure crystal). This is also seen in $\eta_{\mathrm{k}}$, where the $1.8 \%$ impurity has twice the mosaicity of the pure crystal. For this space group, $\mathrm{P} 4_{3} 2_{1} 2$, we would expect that the $\mathrm{h}$ and $\mathrm{k}$ mosaicities would be the same unless the crystal has macroscopic defects. The microgravity crystal, grown in a reduced sedimentation environment, should be even more symmetric. Differences between $\eta_{\mathrm{h}}$ and $\eta_{\mathrm{k}}$ are probably a measure of the uncertainty in the data. In the I direction the mosaicity, $\eta_{1}$, maximizes at the $0.9 \%$ impurity level. The largest decrease in mosaicity occurs for $\eta_{1}$, in both the $3.6 \%$ impurity ground and microgravity samples. The goodness-of-fit values are low, however, suggesting that a three-dimensional anisotropic refinement as a function of $h, k$, and $\mathrm{l}$ is not a suitable model for the system. A similar trend in mosaicity is seen with the anisotropic fit to the growth directions of the crystal but again are not well fit by this model. Crystal growth occurs over a period of hours with changing solution conditions due to the incorporation of protein from the solution into the crystal. The crystal is therefore an integration of the crystallization process over time, and it is perhaps not surprising that there is not a good fit to these simple models. The fit is worst for the $0,0.5$, and $0.9 \%$ microgravity crystals, suggesting that these are more isotropic than anisotropic, a result consistent with the study of microgravitygrown insulin crystals (Borgstahl et al., submitted for publication). Alternative models are now under investigation. To date, the best fit using an anisotropic model was 0.3 for $\mathrm{Mn}$ superoxide dismutase ${ }^{28}$ (i.e., only $30 \%$ of the data could be accurately fitted with the model used).

Also shown in Table 3 are the numbers of reflections and percentages fitted by numbers of Gaussians. The widths of the Gaussians, with standard deviation in thousandths of a degree, are also given. Most samples are best fitted by two Gaussians. The 1.8\% dimer microgravity sample is best fitted with three and the $0 \% \mathrm{E}$ arth sample with a single Gaussian for one swath of data but two for the other. It is noticeable with the mosaicity values of the Gaussians that, in the microgravity case, there is an increase to a maximum Gaussian width and number at $1.8 \%$ followed by a falloff to two narrower Gaussians at greater impurity. The large value for the third Gaussian in the $1.8 \%$ microgravity case indicates it is made up of many smaller domains that are not resolved.

Comparison of the symmetry-rel ated reflections from each data set reveals a trend in mosaicity (Table 4). The 


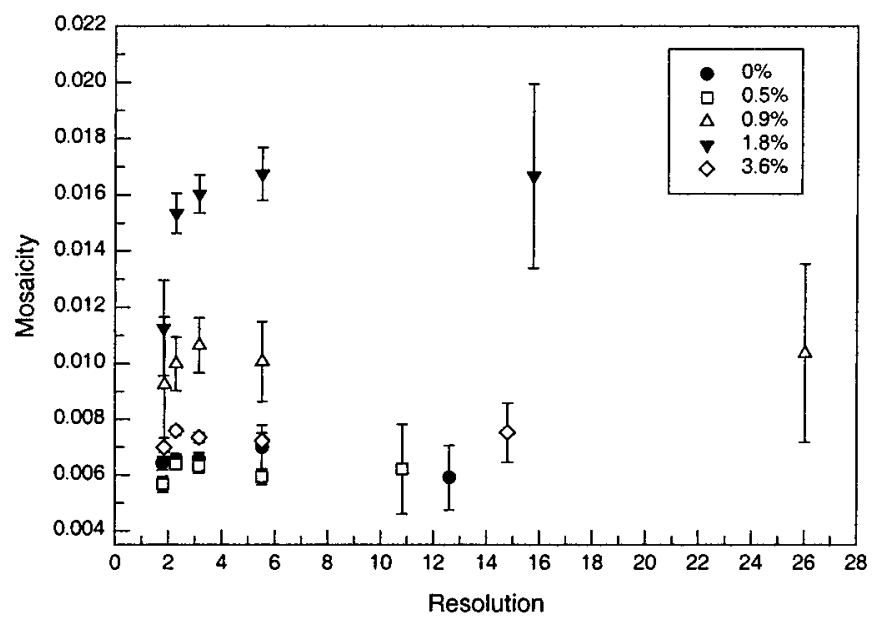

(a) Microgravity

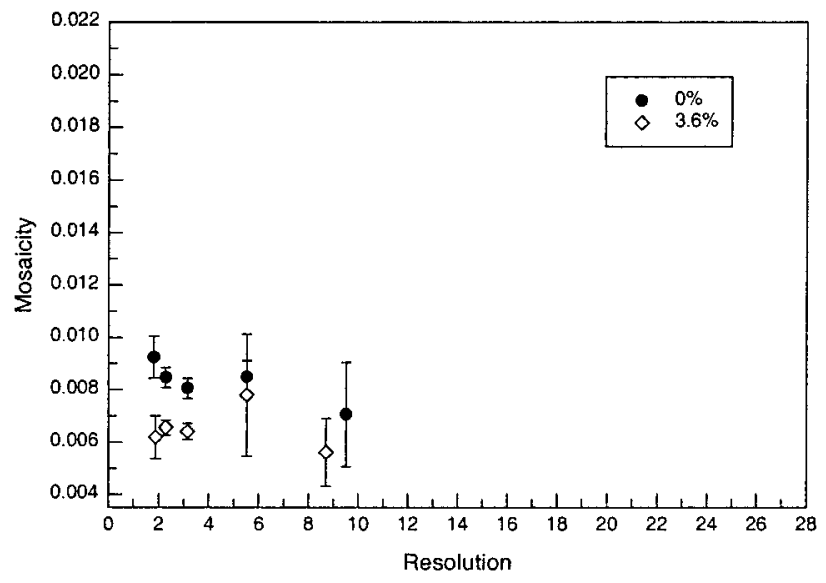

(b) Ground

Figure 6. Mosaicity in degrees plotted against resolution $(\AA)$. For each crystal the data are binned to give an approximately equal number of reflections in each bin Data points represent median point of the bin resolution range. Microgravity samples are shown in (a) and ground samples in (b). While the nonlinearity of the $1.8 \%$ dimer microgravity data is the most pronounced, the size of the $95 \%$ confidence limit error bars make determining the degree of nonlinearity of the other data sets difficult to confirm.

Table 4. Comparison of Symmetry-Related Reflections between Crystalsa

\begin{tabular}{|c|c|c|c|c|c|c|c|c|}
\hline & & \multicolumn{2}{|c|}{ Earth } & \multicolumn{5}{|c|}{ microgravity } \\
\hline & & $0.0 \%$ & $3.6 \%$ & $0.0 \%$ & $0.5 \%$ & $0.9 \%$ & $1.8 \%$ & $3.6 \%$ \\
\hline Earth & $\begin{array}{l}0.0 \% \\
3.6 \%\end{array}$ & $\begin{array}{l}22 \text { rflns } \\
9.8(0.4)\end{array}$ & $\begin{array}{l}22 \text { rflns } \\
4.9(0.6)\end{array}$ & $\begin{array}{l}88 \text { rflns } \\
9.9(0.9) \\
45 \text { rflns } \\
9.4(0.3)\end{array}$ & $\begin{array}{l}56 \text { rflns } \\
9.8(0.4) \\
28 \text { rflns } \\
9.2(0.3)\end{array}$ & $\begin{array}{l}42 \text { rflns } \\
9.8(0.4) \\
13 \text { rflns } \\
10.2(0.2)\end{array}$ & $\begin{array}{l}51 \text { rflns } \\
10.0(0.5) \\
23 \text { rflns } \\
9.9(0.3)\end{array}$ & $\begin{array}{l}95 \text { rflns } \\
9.8(1.0) \\
30 \text { rflns } \\
9.0(0.2)\end{array}$ \\
\hline microgravity & $\begin{array}{l}0.0 \% \\
0.5 \% \\
0.9 \% \\
1.8 \% \\
3.6 \%\end{array}$ & $\begin{array}{l}88 \text { rflns } \\
2.1(1.9) \\
56 \text { rflns } \\
2.1(0.8) \\
42 \text { rflns } \\
7.7(3.6) \\
51 \text { rflns } \\
19.6(2.7) \\
95 \text { rflns } \\
6.3(0.4)\end{array}$ & $\begin{array}{l}45 \text { rflns } \\
0.8(1.0) \\
28 \text { rflns } \\
2.2(0.8) \\
13 \text { rflns } \\
6.7(1.8) \\
23 \text { rflns } \\
5.3(3.8) \\
30 \text { rflns } \\
1.6(1.1)\end{array}$ & $\begin{array}{l}94 \text { rflns } \\
6.1(0.3) \\
70 \text { rflns } \\
7.5(7.4) \\
102 \text { rflns } \\
20.3(5.7) \\
135 \text { rflns } \\
8.5(0.5)\end{array}$ & $\begin{array}{l}94 \text { rflns } \\
4.0(0.7) \\
\\
40 \text { rflns } \\
7.3(3.3) \\
74 \text { rflns } \\
20.2(3.9) \\
75 \text { rflns } \\
8.1(2)\end{array}$ & $\begin{array}{l}70 \text { rflns } \\
1.5(2.1) \\
40 \text { rflns } \\
1.9(1.0) \\
\\
51 \text { rflns } \\
20.9(4.2) \\
81 \text { rflns } \\
8.2(0.3)\end{array}$ & $\begin{array}{l}102 \text { rflns } \\
2.4(2.2) \\
74 \text { rflns } \\
4.5(0.6) \\
51 \text { rflns } \\
7.6(4.7) \\
\\
101 \text { rflns } \\
8.5(0.3)\end{array}$ & $\begin{array}{l}135 \text { rflns } \\
3.7(0.5) \\
75 \text { rflns } \\
5.1(0.2) \\
101 \text { rflns } \\
19.7(7.2) \\
81 \text { rflns } \\
7.6(7.5)\end{array}$ \\
\hline
\end{tabular}

a For each entry the number of symmetry-related reflections is given above the average mosaicity for the row heading. The standard deviation is given in parentheses. Both mosaicity and standard deviation are given in thousandths of a degree.

microgravity samples increase in mosaicity with increasing impurity concentration, reaching a maximum at $1.8 \%$. At $3.6 \%$ the mosaicity is lower than at $1.8 \%$ but still higher than that at $0 \%$ and $0.5 \%$. The Earthgrown crystals also show increased mosaicity with impurity concentration; however, the microgravity crystals show reduced mosacity in comparison to each of their Earth counterparts, with the exception of the 1.8\% microgravity and $0 \%$ Earth.

3.5. E ffect of Precipitant Concentration. In further experimental work, we examined the effect of precipitant concentration on ground crystallization at constant initial supersaturation and temperature at $\mathrm{pH}$ 4.8 on $\mathrm{K}_{\text {eff }}$ (Table 5). No significant increase in $\mathrm{K}_{\text {eff }}$ with increasing salt was observed, with $K_{\text {eff }}$ being on the order of unity. This agrees well with the $K_{\text {eff }}$ value of 0.9 estimated from the work of Thomas et al. ${ }^{36}$ previously. Interestingly, Forsythe and Pusey ${ }^{40}$ find that both the $\{101\}$ and the $\{110\}$ lysozyme face growth rates, at the same supersaturation, decrease with increasing salt concentration. The difference in growth rate due to salt concentration is therefore not enough to provide a significant change in $\mathrm{K}_{\text {eff. }}$
Table 5. Effect of Precipitant Concentration on the Effective Partitioning Coefficient in Ground Crystallization Experiments ${ }^{\mathrm{a}}$

\begin{tabular}{lcccc}
\hline & \multicolumn{4}{c}{$\mathrm{NaCl} \%(\mathrm{w} / \mathrm{v})$} \\
\cline { 2 - 5 } & 2.8 & 3.76 & 5 & 7 \\
\hline $\mathrm{K}_{\text {eff }}$ & 0.6 & 1.0 & 0.9 & 1.1 \\
error & 0.1 & 0.4 & 0.2 & 0.1
\end{tabular}

a The errors were assessed by measurements on duplicate gels. All experiments were conducted at the same initial supersaturation $(\ln (c / s)=2.25)$ and temperature $\left(20^{\circ} \mathrm{C}\right)$.

\section{Discussion}

To date, four impurities have been tested for their effects on diffraction resolution in lysozyme (ovotransferrin, ovalbumin, turkey lysozyme, and the lysozyme dimer). Only the lysozyme dimer is reported to negatively impact X-ray crystal quality. In our study we do not see a favorable significant effect of either microgravity or precipitant concentration on the partitioning coefficients, which remain close to unity-the crystals tend to incorporate similar proportions of dimer and monomer as present in the growth solution. The only trend counter to this is the $0.5 \%$ microgravity crystals, which show preferential incorporation of the dimer. 
Solution factors such as supersaturation, temperature, and even the method of crystallization may affect partitioning quantitatively. For example, our ground partitioning coefficient is a factor of 2 less than the microgravity coefficient reported by Carter et al. ${ }^{10}$ for a similar initial dimer concentration. As partitioning can be so different under different conditions, unless the effect of solution variables on partitioning is well-known for a given system, one cannot know beforehand with any degree of certainty if microgravity will favorably affect the partitioning. The effects of partitioning may also vary from system to system. For example, Lorber et al. ${ }^{15}$ report thaumatin crystals of superior and more uniform crystallographic quality in microgravity in comparison to identical ground controls, while finding no significant difference in macromolecular impurities between crystal content and original thaumatin solution. Long et al.$^{41}$ also report that microgravity-grown crystals of insul in diffracted with higher intensity and to higher resolution with no significant difference in the physical, biochemical, or biological characteristics of the insulin preparation.

For microgravity-grown crystals, the maximum crystal size and intensity of the X-ray reflections both decreased as the dimer concentration increased in the initial solution. These effects level off with increasing impurity concentration, which indicates that as impurity levels are increased, the impurity is less effective. The greatest effect is at low impurity concentrations, and it is interesting to note that many commercial lysozyme preparations contain the dimer in these quantities. ${ }^{42}$ The microgravity results are in contrast to those of the Earth-grown crystals, where increasing dimer concentration has little significant effect on either crystal size or X-ray reflection intensity. In these areas it seems microgravity crystallization is more sensitive to impurities.

Disorder within a crystal can be described in terms of long- and short-range order. Long-range order is seen as localized effects in reciprocal space (i.e., the mosaicity of the reflection). True crystal mosaicity is a measure of physical perfection and is an intrinsic property of the crystal. It is a measure of the angular size of the reflection profile after correction for the effects of the beam nonideality and diffraction geometry. Mosaicity is due to a combination of three causes:38,39 angular misalignment of domains within the crystal, finite domain volume, and lattice strain. In previous microgravity experiments, the reduced crystal mosaicity reported for lysozyme ${ }^{4}$ and thaumati ${ }^{5}$ were observed to be from the increase of domain sizes within the crystals. ${ }^{39}$ The flight samples reported in this study were consistently larger than the ground samples, and it would appear that this increase in volume is also reflected in domain sizes.

Angular misalignment and domain size effects are independent of resolution; however, lattice strain effects are resolution-dependent. Therefore, analysis of the mosaicity data against resolution gives information on the degree of lattice strain. This analysis for microgravity samples (Figure 6 ) shows that the $1.8 \%$ sample indicates lattice strain. The $0,0.5$, and $3.6 \%$ samples show no strain. For the $0.9 \%$ impurity sample, it is difficult to say within the bounds of error. What is interesting is the reduction in mosaicity with $3.6 \%$ impurity, although one should note that this does not imply an improvement in structural data. What is happening here? The gradual increase in mosaicity from $0 \%$ to $0.9 \%$ is indicative of a reduction in domain size or an increase in misalignment-without the additional experimental evidence of reciprocal space mapping, topography, or a combination 39,43 it is impossible to tell which. Impurity incorporation appears to eventually cause stress on the lattice, as evidenced by the resolution variation of the $1.8 \%$ microgravity sample. This appears to be relieved as the impurity concentration increases. The symmetry-related reflection mosaicity analysis (Table 4) shows that although the mosaicity of the $3.6 \%$ sample is lower than that at $1.8 \%$, it is still higher than that of the lower impurity samples $(<0.9 \%)$. The reduction of internal domain stress may therefore result in reduced domain size with some increased domain misalignment. The $1.8 \%$ microgravity sample is clearly an outlier. Other explanations are possible, and it is impossible to rigorously rule out experimental effects, but reduced domain size with some increases in misalignment appears to be the most straightforward explanation of our data. While the devel opment of the procedures used in this study ${ }^{28,29}$ has made possible the use of hundreds of indexed reflections to determine the mosaicity, it should be noted that only a single crystal for each impurity condition was used. This was due to the limited availability of synchrotron beam time and the length of the experiment. The X-ray analysis of the effects of impurity on crystal mosaicity should therefore be interpreted with caution until confirming experiments are performed. However, the partitioning coefficients were measured with many crystals and they represent a statistically valid result.

Finally, the largest crystals with the best diffraction resolution, the highest signal-to-noise ratio for the highest diffraction resolution range data, and the lowest symmetry-related reflection mosaicity were the microgravity crystals grown from pure solution. The superiority of these crystals over their Earth-grown counterparts is, as far as we can determine, independent of the effect of impurities.

\section{Conclusions}

For this macromolecule system the improvement in microgravity is optimized by preventing a specific impurity, commonly found in CEWL preparations, from entering the crystal lattice. In this case ground growth does not seem to be as sensitive to this impurity. As the gains obtained in microgravity are easily lost if this dimer is incorporated into the crystal lattice, optimizing improvement in microgravity therefore requires the purification of the macromol ecule solution to the highest level possible. While there is a reported instance of microgravity aiding in the partitioning of this impurity, ${ }^{10}$ the partitioning process seems to be heavily condition- and technique-dependent and is also complex, as evidenced by the markedly different results presented here. For systems that are not as well-known as CEWL, purifying the samples to the highest level available will likely increase chances for improvement of crystal quality in microgravity. This is not a surprising result and has been a protocol followed in ground-based 
crystallization for many decades. Microgravity should not be seen as a step to replace good biochemical practice but may be useful in situations where solution impurities are formed during the crystallization process. Partitioning seems to be a complex phenomenon.

Acknowledgment. This work was funded by NASA Grants NCC8-66 and NAG8-1380. Fresh eggs were supplied by Madison County Poultry Farm Inc., Madison, AL 35758. E.H.S. and E.L.F. are contractors to NASA via the Universities Space Research Association. R.A.J . is a contractor to NASA through the University of Alabama in Huntsville and L.C. through the University of Toledo, Toledo, $\mathrm{OH}$. Research at the University of Colorado and Instrumentation Technology Associates was funded by NASA Grant NAG8-1165. This work is based in part upon research conducted at the Stanford Synchrotron Radiation Laboratory (SSRL), which is funded by the Department of Energy, Office of Basic Energy Sciences. The Biotechnology Program is supported by the National Institutes of Health, the National Center for Research Resources, the Biomedical Technology Program, and the Department of Energy, Office of Biological and Environmental Research. M. Pokross is acknowledged for his help and assistance in this work.

Supporting Information Available: Text describing the estimation of dimer partitioning coefficients by mass balance calculations. This material is available free of charge via the Internet at http://pubs.acs.org.

\section{References}

(1) Kundrot, C. E.; J udge, R. A.; Pusey, M. L.; Snell, E. H. Cryst. Growth Des. 2001, 1, 87.

(2) McPherson, A.. J . Phys. D, Appl. Phys. 1993, 26, B104B112.

(3) DeLucas, L. J .; Long, M. M.; Moore, K. M.; Rosenblum, W. M.; Bray, T. L.; Smith, C.; Carson, M.; Narayana, S. V. L.; Harrington, M. D.; Carter, D.; Clark, A. D., J r.; Nanni, R. G.; Ding, J .; J acobo-Molina, A.; Kamer, G.; Hughes, S. H.; Arnold, E.; Einspahr, H. M.; Clancy, L. L.; Rao, G. S. J .; Cook, P. F.; Harris, B. G.; Munson, S. H.; Finzel, B. C.; McPherson, A.; Weber, P. C.; Lewandowski, F. A.; Nagabhushan, T. L.; Trotta, P. P.; Reichert, P.; Navia, K. P.; Wilson, K. P.; Thomson, J . A.; Richards, R. N.; Bowersox K. D.; Meade, C. J .; Baker, E. S.; Bishop, S. P.; Dunbar, B. J .; Trinh, E.; Prahl, J .; Sacco, A., J r.; Bugg, C. E. J . Cryst. Growth 1994, 135, 183-195.

(4) Snell, E. H.; Weisgerber, S.; Helliwell, J . R.; Weckert, E.; Hölzer, K.; Schroer, K. Acta Crystallogr. 1995, D51, 10991102.

(5) Ng, J . D.; Lorber, B.; Giegé, R.; Koszelak, S.; Day, J .; Greenwood, A.; McPherson, A. Acta Crystallogr. 1997, D53, 724-733.

(6) Hilgenfeld, R.; Liesum, A.; Storm, R. J . Cryst. Growth 1992 122, 330-336.

(7) Vaney, M. C.; Maignan, S.; Riès-Kautt, M.; Ducruix, A. Acta Crystallogr. 1996, D52, 505-517.

(8) Ries-Kautt, M.; Broutin, I.; Ducruix, A.; Shepard, W.; Kahn, R.; Chayen, N.; Blow, D.; Paal, K.; Littke, W.; Lorber, B.; Theobald-Dietrich, A.; Giegé, R. J . Cryst. Growth 1997, 181, 79-96.

(9) Helliwell, J . R.; Snell, E. H.; Weisgerber, S. In Proceedings of the 1995 Berlin Microgravity Conference; Ratke, L. Walter, H., Feuerbache, B., Eds.; Springer-Verlag: Berlin, 1996; pp 155-170.

(10) Carter, D. C.; Lim, K.; Ho, J . X.; Wright, B. S.; Twigg, P. D.; Miller, T. Y.; Chapman, J .; Keeling, K.; Ruble, J .; Vekilov, P. G.; Thomas, B. R.; Rosenberger, F.; Chernov, A. A. J . Cryst. Growth 1999, 196, 623-627.

(11) Strong, R. K.; Stoddard, B. L.; Arrott, A.; Farber, G. K. J . Cryst. Growth 1992, 119, 200-214.

(12) Giegé, R.; Dock, A. C.; Kern, D.; Lorber, B.; Thierry, J . C.; Moras, D. J . Cryst. Growth 1986, 76, 554-561.
(13) Skouri, M.; Lorber, B.; Giegé, R.; Munch, J . P.; Candau, J . S. J . Cryst. Growth 1995, 152, 209-220.

(14) J udge, R. A.; Forsythe, E. L.; Pusey, M. L. Biotechnol Bioeng. 1998, 59, 776-785.

(15) Lorber, B.; Sauter, C.; Robert, M. C.; Capelle, B.; Giegé, R. Acta Crystallogr. 1999, D55, 1491-1494.

(16) Caylor, C. L.; Dobrianov, I.; Lemay, S. G.; Kimmer, C.; Kriminski, S.; Finkelstein, K. D.; Zipfel, W.; Webb, W. W.; Thomas, B. R.; Chernov, A. A.; Thorne, R. E. Proteins: Struct., Funct., Genet. 1999, 36, 270-281.

(17) Hirschler, J .; Halgand, F.; Forest, E.; Fontecilla-Camps, J . C. Protein Sci. 1998, 7, 185-192.

(18) Hirschler, J .; F ontecilla-Camps, J . C. Acta Crystallogr. 1996, D52, 806-812.

(19) Bhamidi, V.; Hanson, B. L.; Edmundson, A.; SkrzypczakJ ankun, E.; Schall, C. J . Cryst. Growth 1999, 204, 542552.

(20) Back, J . F. Biochim. Biophys. Acta 1984, 799, 319-321.

(21) McPherson, A.; Malkin, A. J .; Kuznetsov, Y. G.; Koszelak, S.; Wells, M.; J enkins, G.; Howard, J .; Lawson, G. J . Cryst. Growth 1999, 196, 572-586.

(22) Aune, K. C.; Tanford, C. Biochemistry 1969, 8, 4579-4585.

(23) Shugar, D. Biochim. Biophys. Acta 1962, 8, 302-309.

(24) Mayes, E. L. V. In Methods in Molecular Biology; Walker, J. M., Ed.; Humana Press: Clifton, NJ , 1984; Volume 1 (Proteins), pp 33-39.

(25) Holemans, J .; Cassanto, J . M.; Moller, T. W.; Cassanto, V. A.; Rose, A.; Luttges, M.; Morrison, D.; Todd, P.; Stewart, R.; Korszun, Z. R.; Deardorff, G. Microgravity Quarterly 1991, 1, 235-247.

(26) J udge, R. A.; Frazier, T.; J acobs, R.; Pusey, M. L. Biophys. J. 1999, 77, 1585-1593.

(27) Thomas, B. R.; Chernov, A. A.; Vekilov, P. G.; Carter, D. C. J . Cryst. Growth 2000, 211, 149-156.

(28) Bellamy, H. D.; Snell, E. H.; Lovelace, J .; Pokross, M. Borgstahl, G. E. O. Acta Crystallogr. 2000, D56, 986-995.

(29) Lovelace, J .; Snell, E. H.; Pokross, M.; Arvai, A.; Nielson, C.; Xuong, N.-H.; Bellamy, H. D.; Borgstahl, G. E. O. J . Appl. Crystallogr. 2000, 33, 1187-1188.

(30) Leslie, A. G. W. J nt CCP4/ ESF-EACMB Newslett. Protein Crystallogr. 1992, 26.

(31) Collaborative Computational Project, Number 4. Acta Crystallogr. 1994, D50, 760-763.

(32) Ferrer, J . L.; Roth, M. J . Appl. Crystallogr. 1998, 31, 523532.

(33) Long, M. M.; DeLucas, L. J .; Smith, C.; Carson, M.; Moore, K.; Harrington, M. D.; Pillion, D. J .; Bishop, S. P.; Rosenblum, W. M.; Naumann, R. J .; Chait, A.; Prahl, J .; Bugg, C. E. Microgravity Sci. Technol. 1994, 7, 196-202.

(34) Snell, E. H.; Boggon, T. J .; Helliwell, J . R.; Moskowitz, M E.; Nadarajah, A. Acta Crystallogr. 1997, D53, 747-755.

(35) Boggon, T. J .; Chayen, N. E.; Snell, E. H.; Dong, J .; Lautenschlager, P.; Potthast, L.; Siddons, D. P.; Stojanoff, V.; Gordon, E.; Thompson, A. W.; Zagalsky, P. F.; Bi, R.-C.; Helliwell, J . R. Philos. Trans. R. Soc. London, Ser. A 1998, 356, 1045-1061.

(36) Thomas, B. R.; Vekilov, P. G.; Rosenberger, F. Acta Crystallogr. 1998, D54, 226-236.

(37) Carter, D. C.; Wright, B. S.; Twigg, P. D.; Miller, T. Y.; Chapman, J .; Twigg, P.; Keeling, K.; Moody, K.; White, M.; Click, J .; Ruble, J.; Ho, J . X.; Adcock-Downey, L.; Bunick, G.; Harp, J. J . Cryst. Growth 1999, 196, 602-609.

(38) Nave, C. Acta Crystallogr. 1998, D54, 848-853.

(39) Boggon, T. J .; Helliwell, J . R.; J udge, R. A.; Moorcroft, D.; Olczak, A.; Siddons, D. P.; Snell, E. H.; Stojanoff, V. Acta Crystallogr. 2000, D56, 868-880.

(40) Forsythe, E.; Pusey, M. L. J . Cryst. Growth 1994, 139, 89 94.

(41) Long, M. M.; Bishop, J . B.; Nagabhushan, T. L.; Reichert P.; Smith, G. D.; DeLucas, L. J .J . Cryst. Growth 1996, 168, 233-243.

(42) Thomas, B. R.; Vekilov, P. G.; Rosenberger, F. Acta Crystallogr. 1996, D52, 776-784.

(43) Volz, H. M.; Matyi, R. J . Acta Crystallogr. 2000, D56, 881889.

(44) Vekilov, P. G.; Monaco, L. A.; Thomas, B. R.; Stojanoff, V.; Rosenberger, F. Acta Crystallogr. 1996, D52, 785-798.

CG0055474 